DIVISION OF THE HUMANITIES AND SOCIAL SCIENCES CALIFORNIA INSTITUTE OF TECHNOLOGY

PASADENA, CALIFORNIA 91125

RENEGOTIATION AND THE FORM OF EFFICIENT CONTRACTS

Jerry Green

Harvard University

Jean-Jacques Laffont

GREMAQ and California Institute of Technology

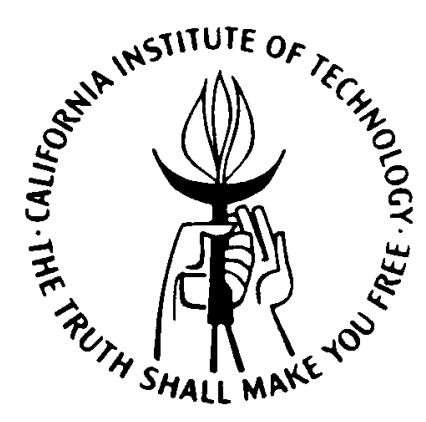




\title{
RENEGOTIATION \\ AND THE \\ FORM OF EFFICIENT CONTRACTS*
}

\author{
by \\ Jerry Green \\ Harvard University \\ and \\ Jean-Jacques Laffont \\ GREMAQ and California Institute of Technology
}

\section{$\underline{\text { Abstract }}$}

Two parties may agree to a mutually binding contract that will govern their behavior after an uncertain event becomes known. As there is no agent who can both observe this uncertain outcome and enforce the contract, contingent agreements are precluded. However, the parties recognize that the uncertain event will be common knowledge for them, and that they will be able to renegotiate the contract voluntarily, provided that they both gain in doing so. When structuring the original contract they can foresee this renegotiation phase. Efficient contracts are those that perform best, when taking this into account.

This paper studies the form of such efficient contracts. It is shown that it is always better to have a contract than it is to have none, no matter which party has the preponderence of bargaining strength in the renegotiation phase. We also study whether renegotiation can substitute completely for the absence of contingent contracts. We characterize a family of cases where it can. And we present some "second-best" results in others, where it cannot.

\footnotetext{
* This research was supported by National Science Foundation grant number IRI-85-07291. The authors thank
} Michael Whinston and John Moore for comments on the earlier version. 


\section{Introduction}

In this paper we discuss the process of contract formation and contract revision in a two-party relationship. At the time that the contract can first be written some uncertainty about the future is present. However, although both of the contracting parties can observe the resrilution of this uncertainty before any payoff-relevant actions are required, we assume that it is not possible to implement contracts which are specified ex ante, before the uncertainty is resolved, and are contingent upon these outcomes. This contractual "incompleteness" or "imperfection" is at the heart of the phenomena we study and is justified as follows. As parties have conflicting interests the contract needs to be enforced by some third party, or outside agency, who has, or is invested with, the power to punish the participants for failing to comply" with its provisions. A "full" specification of the contractual relations would include the actions to be taken in various contingencies and the enforcement procedures to be used. In our model, the outside enforcement agency cannot observe the resolution of uncertainty at all. This is a way of capturing the more realistic viewpoint of limited, costly, observability which more accurately characterizes reality. (Further discussion of the use of this non verifiability assumption is given below.)

Having stated what the enforcement agency cannot do, we must be explicit about the powers with which it is endowed. We assume that the enforcement agency can cibserve the chosen action and can compare it to the contractual specifications. These specifications can be a precise description of unique actions that have been agreed upon, or, more generally, can consist of a set of allowable actions within which one of the parties has the full discretion to choose the actual result. If the chosen action violates these specifications, a large (unspecified) punishment can be, inflicted. For those contracts in which limited control is delegated to one side or the other, the action chosen within the allowable range will be that in the best interest of the controlling party. Moreover, the agency can observe which party has been given the power of choosing the "renegotiated" contract. 
One principal focus of this paper is to present a theory that predicts whether a contract will be signed ex ante. Assume that a contract, if signed, can still be voluntarily renegotiated. As both parties can correctly anticipate the outcome of renegotiation, the end result will be sensitive to information. But the renegotiation will be conducted under the constraint that the status quo is that generated by the first contract. Delaying agreement by not writing an initial contract, means that the ex post outside opportunity of the agent is the same status quo level that was available ex ante. Since a first period contract generates status quo levels which are sensitive to information, the comparison between the optimal ex-ante contract, followed bv renegotiation, and no contract followed by an ex post efficient agreement is not obvious.

A second principal focus of the paper is the issue of renegotiation of contracts. When a fully optimal contract is not possible at the initial date, it is natural to presume that ex post inefficiencies will be eliminated by mutually advantageous renegotiation. The initial contract determines the baseline from which the subsequent bargaining will take place. In a situation of perfect information, such as that arising after the uncertainty is resolved and is observable by both parties, it is natural to believe that efficient agreement will result, and it is also natural for the baseline or status quo to influence which ex post efficient point, among those superior for both players, will be selected. We inquire when the first best can be reached through renegotiation.

Before outlining our results it may be useful to quickly review the related literature. The lack of verifiability by a third party of information known by two parties is usually accepted as a good reason for the impossibility of having contracts contingent on that information. The implementation literature (Maskin(1985)) suggests that even in that case complex games could be constructed whose Nash equilibria would implement first best contingent allocations. So non verifiability is not enough and must be supplemented by an assumption of restricted complexity or bounded rationality. No effort is usually made to justify rigorously this second assumption (see Huberman and Kahn (1986) for such an 
attempt).

The assumption of non verifiability is usually traced back to Bull (1983) who shows that a non-contingent non-enforceable contract can survive in a world where markets are very incomplete and only bundles of commodities (labor and effort) can be traded. The role of reputation and the use of hostages to mitigate the absence of enforcement mechanisms has been studied but their effect is limited to rather special circumstances.

One line of research attempts to show why non-enforceable contracts can survive because they are self enforceable. For example, Bull (1987) shows that a contract where a firm and a worker behave honestly can exist because it is a Nash equilibrium of the induced repeated moral hazard problem. The work on repeated games is relevant to this question but its reliance on very long relationships restricts its applicability.

The lack of verifiability of some variables does not eliminate the possibility of contracting conditionally on a restricted set of publically observed variables. Contracts which delegate control to one of the parties either unconditionally or conditionally on some observable variables are particularly interesting because they can make use of the acquisition of information achieved by the controlling party. Such contracts have been exploited to provide a basis for a theory of firm integration (Grossman and Hart (1986)) or to explain the structure of debt which has an influence on the publically observable event bankruptcy used to reallocate control (Aghion and Bolton (1986)). Grossman and Hart (1987) apply the same sort of idea to explain the charter of a widely held corporation.

An alternative to a contract based on limited verifiable information is to renegotiate given the status quo provided by an initial contract. Hart and Moore (1985) study trade between two agents who do not know yet their valuation of the transaction. Courts can only observe the agreed upon prices and whether or not a transaction has taken place. A first contract is signed conditionally on these observable variables and anticipating a renegotiation once the valuations are known - in general the first best is not achievable. They continue to assume that messages sent ex post by agents are verifiable, reaching the 
conclusion of the implementation literature that a complex game can be constructed to implement the first best.

Huberman and Kahn (1986a) study a model where the action of one party is not verifiable and where the suboptimal initial contract is used to protect a party from the non verifiable action that the other party could take. As in Hart and Moore the initial contract signed serves as a status quo position for the renegotiation ex post.

Finally, Grout (1984) and Tirole (1986) have studied the impact of contractual incompleteness on the level of investment in the relationship.

We consider a two party model where the contingent and non verifiable event affects only the utility function of one party.

Our model is close to the first part of Hart and Moore (1985) in that the court's ability to observe is very limited. We assume that the court can only observe a set of agreed prices and quantities ex ante among which the party sensitive to the information will be able to select once informed, and the court can observe to which agent the control of the renegotiated price and quantity pair has been given.

Contrary to Hart and Moore who look at Nash equilibria, we use the Stackelberg assumption of the principal-agent literature and assume that the principal, whose utility function is not affected by information, is the Stackelberg leader. He designs the game to play by choosing one of the following options:

a) no contract ex ante and choosing a contract ex post.

b) choosing ex ante a set of price-quantity pairs among which the agent, once informed, selects a pair to be used as the status quo of the renegotiation in which the principal retains full control.

c) choosing a price-quantity contract used as the status quo in the renegotiation in which the agent is in control.

This set of games exhaust the possibilities under the limited observability assumption we make on the court. 
Section 2 defines the model we use and shows that the game in which the control of renegotiation is given to the agent (game $c$ above) is a special case of the game b. Section 3 characterizes the first best allocations. We show in section 4 that, under quite general circumstances we can predict that a contract will be signed ex ante because no contract (game a) is dominated by a well chosen game $c$ and therefore by a game b according to the result of section 2. Section 5 studies the general second best optimization problem that the principal must solve and characterizes some situations in which the first best is implementable. Examples are discussed in section 6. 


\section{The Model}

\section{A. Contracts}

The two players will be called the principal and the agent. They choose two decision variable, $x$ and $t$. In some applications $x$ will be a quantity of some economic good, perhaps produced by the principal and consumed by the agent, and $\mathrm{t}$ will be a monetary transfer from the agent to the principal. In other applications, however, their interpretation may be quite different.

The two players are uncertain about a random variable $\theta$, whose distribution they believe to be $F$. This variable is payoff relevant only to the agent.

Thus the two players von Neumann-Morgenstern utility functions are

$$
\begin{gathered}
U_{P}=\mathrm{f}(\mathrm{t}, \mathrm{x}) \\
\mathrm{U}_{\mathrm{A}}=\mathrm{u}(\mathrm{x}, \mathrm{t}, \theta)
\end{gathered}
$$

We will always assume that $f_{t}>0, f_{x}<0, u_{x}>0, u_{t}<0$ and $u_{\theta}>0$. This last condition means that higher values of $\theta$ are, at constant $(x, t)$, always "good news". The other assumptions follow quite naturally in the interpretation given above, and in others discussed below. We will also assume the usual single crossing property,

$$
\frac{\partial}{\partial \theta}\left[-\frac{{ }^{u} x}{u_{t}}\right]>0 \text {. }
$$

In a world of costless contracting and perfect contract enforcement the players would agree on a contingent arrangement regarding both $\mathrm{x}$ and $\mathrm{t}$ as a function of $\theta$. This paper concerns cases in which such a plan is not feasible, at least by means of a direct contract fixed before $\theta$ becomes known. Let us therefore be precise about the type of contracts that are feasible, and about the structure of the process that determines how the players can enforce and modify the contract after they both learn the value of $\theta$.

We assume that if a contract is offered at all, it is selected by the principal in such a way that the agent will achieve an expected utility of $w$, his reservation level of utility. 
One option the principal retains is to offer no contract at all to the agent. If this happens, the principal must offer the agent a proposal, after $\theta$ becomes know, that still achieves this reservation value of $\bar{w}$.

A contract at the initial point in time can have two types of provisions. The first specifies an outcome, or a set of outcomes, that are agreed upon. The enforcement agency, which we sometimes call a "court", can.observe whether the actual outcome coincides with, or, more generally, lies in, this contractual stipulation. The court has the power to enforce this provision - perhaps by inflicting a large unspecified punishment if it is violated unless the parties voluntarily agree to replace this contract with some other agreement. In this sense the agreed upon outcomes are binding upon both parties.

If this contractual provision specifies a set of outcomes, it is understood that the agent retains the right to choose among them and to insist upon the outcome that is best for himself, unless a mutually superior outcome arises in the renegotiation phase. Note that it would never be beneficial to specify a set of outcomes and give the principal the right to chonse among them because, as the principal's utility is independent of $\theta$, the sub optimal members of this set would be irrelevant.

To summarize the first phase of a contract, there are two possible specifications. Either a set of outcomes (perhaps a singleton) is delineated and the agent is given control among them, or a single outcome is specified upon which the principal can insist.

At this point $\theta$ becomes known by both parties, but not by the court. The reason for this is that $\theta$ may actually be quite a complex set of circumstances. Although they may be understood perfectly well by the parties themselves, neither side may be able to actually prove to a court exactly what these circumstances are, or at least this may be infeasible in a reasonable amount of time and without much cost.

After $\theta$ is revealed, the parties have the opportunity to renegotiate. The rules of the bargaining games that we consider are particularly simple. If the agent is given control over the possible outcomes at the first stage, the principal is given the po'ver at this stage 
to make a take-it-or leave-it offer that, if rejected, will result in the agent's original choice being enforced by the court. Conversely, if it is the principal who is guaranteed the right to insist upon a particular outcome, then the agent is given the exclusive right to hold the principal down to that level of utility in the renegotiation phase.

Thus there are two distinct forms of contract. The extensive form games corresponding to these contracts are shown in figures 1 and 2. The extensive form of the game corresponding to no contract is given in figure 3.

In either form of contract the court must be able to observe the outcome chosen by the party given control; it must be able to compare this outcome to the specified set of outcomes; and it must be able to preserve the right of the party specified as the . Stackelberg leader in the renegotiation phase. If the court is given these powers and no others - for example the court cannot observe the strategies played in any normal or extensive form game the players might put in place by virtue of their contract - then these two forms of contract exhaust all the possiblities.

One might think that our specification of such a simple form of renegotiation - the making of a take-it-or-leave-it offer-is too simple and unrealistic. Perhaps the parties will have recourse to some other form of coordination in which a different bargaining outcome is chosen, say the Nash solution with the original point being the disagreement outcome. This is, of course, possible. Perhaps an interesting theory could be developed along these lines. However any such a renegotiation phase, if specified as an extensive form game, will necessarily involve strategic choices by both players. If these strategies are themselves unobservable by the court, there will be no way to insure that this other bargaining solution is, in fact, the result of such renegotiation. ${ }^{1}$ Thus, given our assumptions about what is and what is not observable by the court, the two contractual

1And Maskin (1985), Moore and Repullo (1985) have shown that if strategies in a game the players agree to play are observable and verifiable by the court, then the first-best solution is obtainable under fiarly general conditions. But the motivation our paper is that their strategies are likely to be unverifiable. 
forms described above exhaust all possibilities. 


\section{B $\underline{\text { Pavoffs }}$}

Many of our results are obtained with the general payoff function ' $? .1$ ), possibly with the addition of some mild and well known qualitative conditions. Two special models suggest themselves, and particular results that compare the efficiency of alternative contractual forms in these models will be given in section 5 and 6 .

The first is a model of a buyer whose valuation function for a good he is purchasing is parameterized by $\theta$. The buyer is the agent, $x$ is the quantity purchased and $t$ is the amount of money paid. If the buyer is risk-neutral in money, then his utility is

$$
\mathrm{U}_{\mathrm{A}}=-\mathrm{t}+\mathrm{u}(\mathrm{x}, \theta)
$$

The seller, assumed to be risk averse, produces the good with constant returns to scale. Without loss of generality we can set unit cost at unity. Thus,

$$
U_{P}=f(t-x)
$$

The second model concerns a firm and a worker. The worker's utility for income, $x$, depends on $\theta$. Perhaps the worker does not know the result of his investments in his non-human wealth; or perhaps some aspects of his personal circumstances, such as future kealth or the tastes of his family members, are unknown. Then, if the worker is risk-neutral in his effort, $t$,

$$
\mathrm{U}_{\mathrm{A}}=-\mathrm{t}+\mathrm{u}(\mathrm{x}, \theta)
$$

as above. The principal is the firm. The firm's profits are concave and increasing in the worker's effort. Hence,

$$
\mathrm{U}_{\mathrm{P}}=\mathrm{f}(\mathrm{t})-\mathrm{x}
$$

[Note that here the roles of $t$ and $x$ are reversed from that of the more usual notation.] 


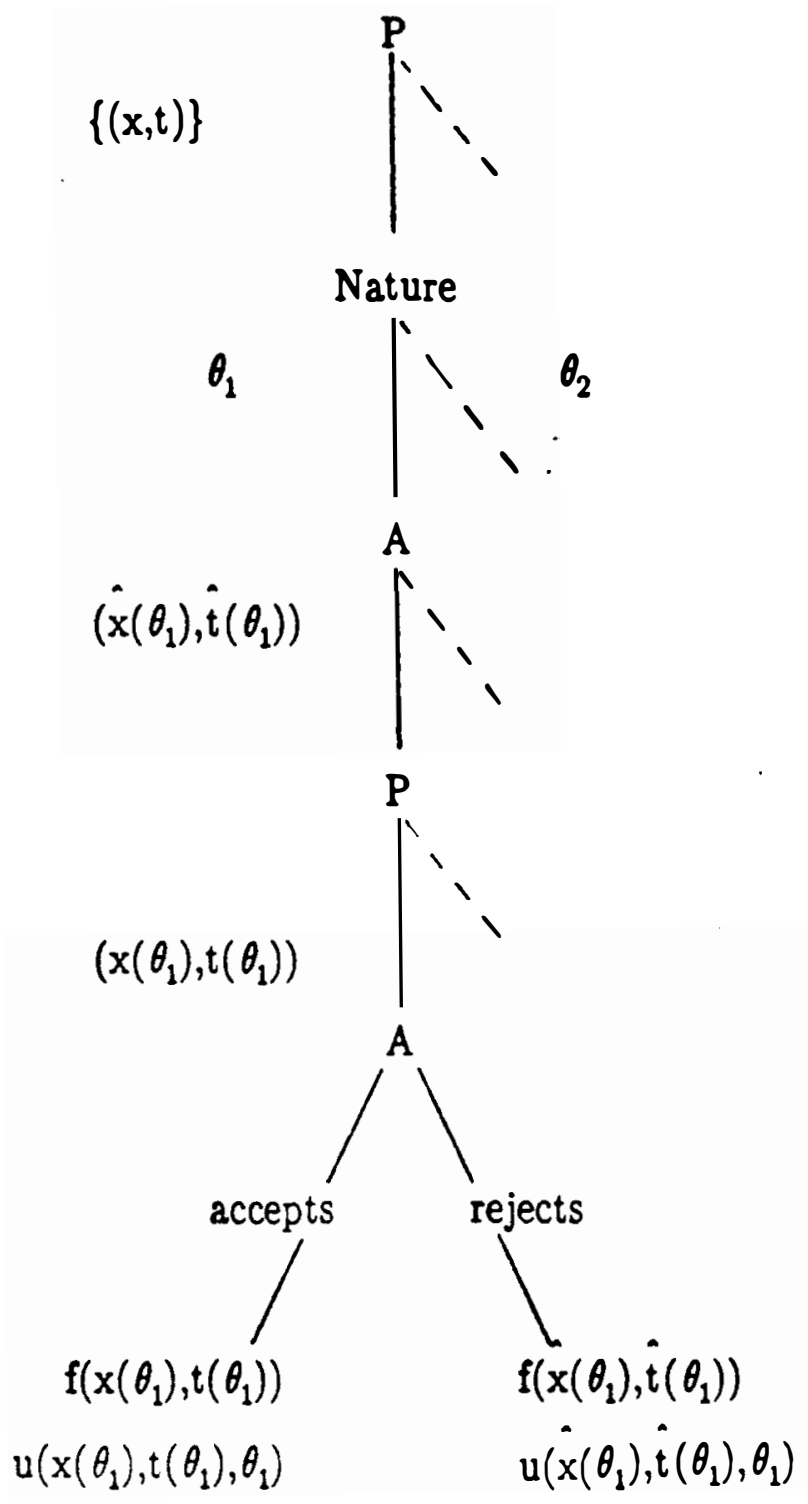

FIGURE 1

DELEGATION AND P-LED RENEGOTIATION 


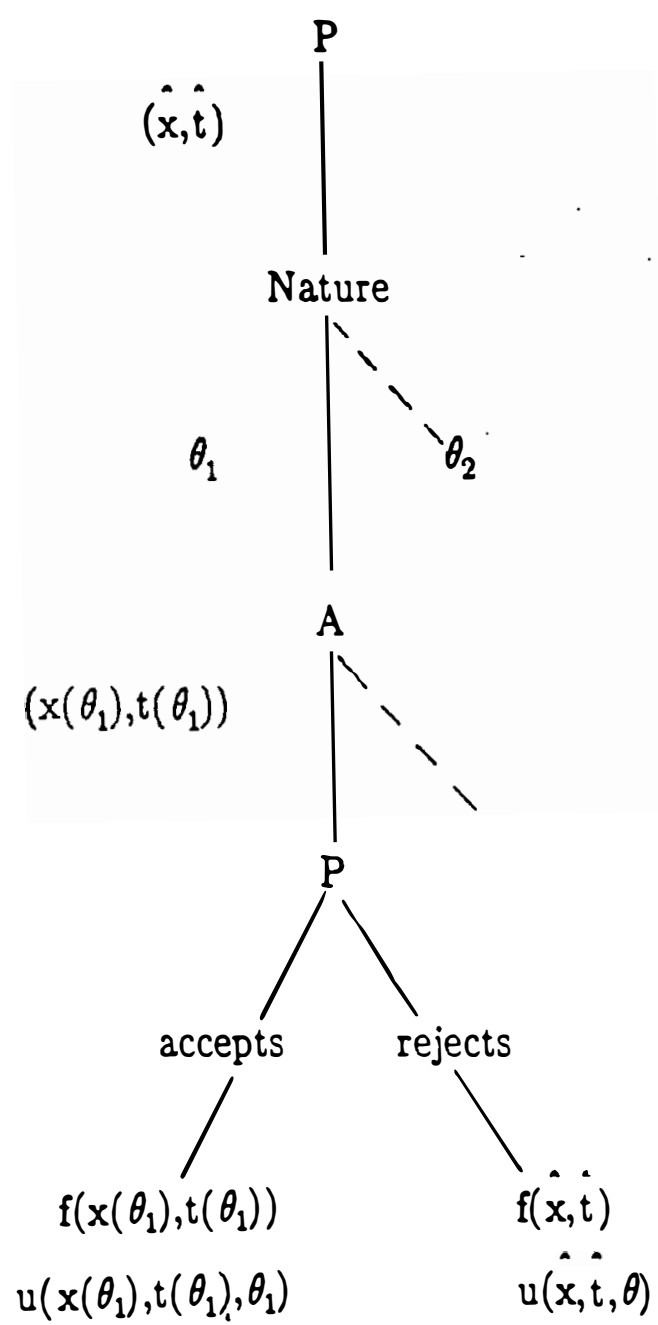

FIGURE 2

A-LED RENEGOTIATION 


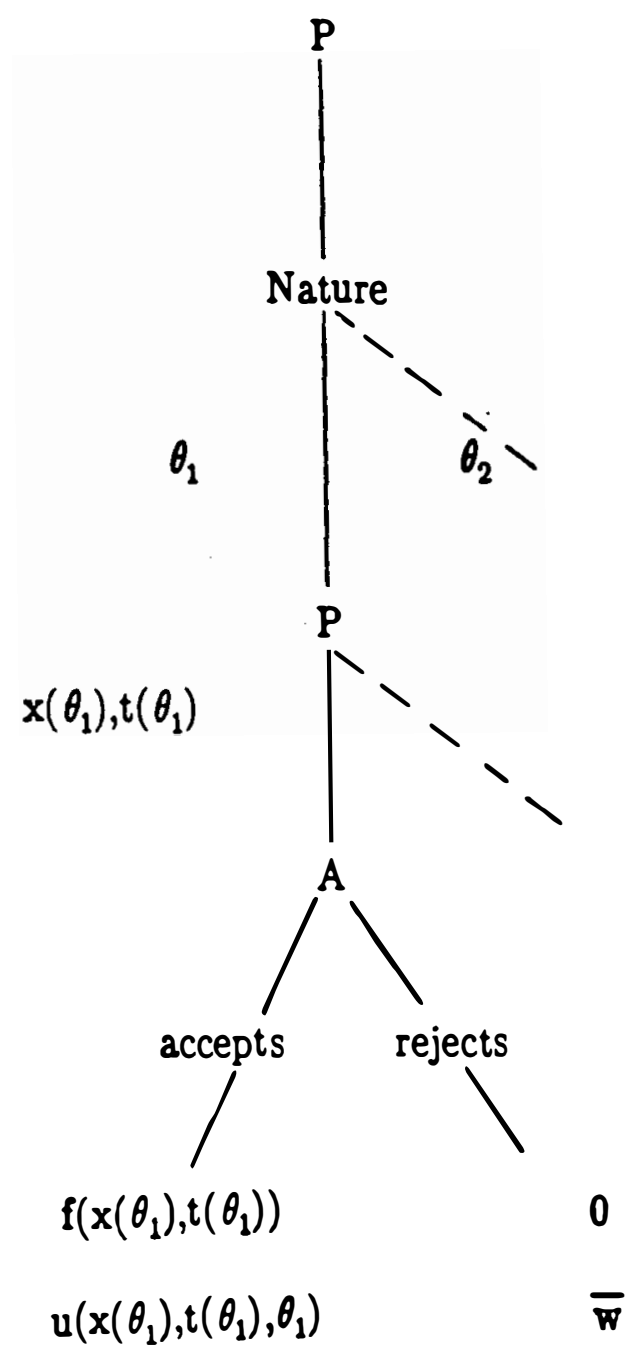

FIGURE $\underline{3}$

NO CONTRACT 
C. General Results About the Efficiencv of Alternative Contractual Forms

Let us introduce a somewhat abbreviated terminology for the contractual forms discussed in section $2 \mathrm{~A}$. When the agent is delegated authority to choose the outcome within some set and the principal has the upper hand in the renegotiation phase, we will

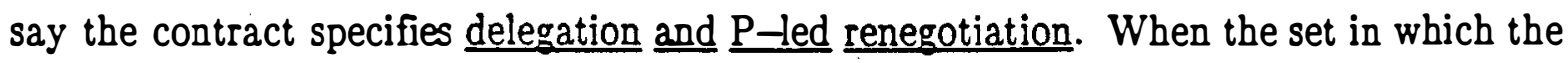
agent can select is reduced to a singleton, we say that delegation and P-led renegotiation reduces to a simple contract and P-led renegotiation. When the agent is given the power in the renegotiation phase we will say that the contractual form is A-led renegotiation. Finally, if no agreement is made ex ante we will call it no contract - that is, "no contract" will itself be considered a form of contract.

The results of any of these contractual forms will be a pair of realizations $x(\theta), t(\theta)$, as determined by the rules of these games and the self-interest of the players. We will say, for example, that $x(\theta), t(\theta)$ is implementable via delegation and $\underline{P}$-led renegotiation if there is a contract of this form that results in these outcomes. Likewise for implementability via the other forms of contract.

Theorem 1

The utility reached by the principal in a contract with A-led renegotiation can be reached or exceeded for all $\theta$ in a contract with delegation and $\mathrm{P}$-led renegotiation. $\underline{\text { Proof }}$

In the proof, we first show that if $x(\theta), t(\theta)$ is implementable via $A$-led renegotiation then it is also implementable in the ordinary sense of incentive compatibility (as if $\theta$ were the private information of the agent). Then we show that if $x(\theta), t(\theta)$ is incentive compatible, then there will exist another pair $\overline{\mathbf{x}}(\theta), \overline{\mathrm{t}}(\theta)$ that is implementable via delegation and $\mathrm{P}$-led renegotiation that is preferred by the principal for all $\theta$. The arguments are straightforward. Take $\mathrm{x}(\theta), t(\theta)$ implementable via A-led renegotiation. Then there exists $\dot{x}, \dot{t}$ such that, 


$$
f(\dot{t}, \dot{x})=f(t(\theta), x(\theta)) \quad \text { for any } \theta
$$

and

$$
u(x(\theta), t(\theta), \theta) \geq u(x, t, \theta)
$$

for all $(x, t)$ such that $f(t, x) \geq f(\hat{t}, \dot{x})$. This is precisely the condition for the incentive compatibility of $x(\theta), t(\theta)$. Since, for $\theta=\theta$, we have

$$
u(x(\theta), t(\theta), \theta) \geq u\left(x\left(\theta^{\prime}\right) t\left(\theta^{\prime}\right), \theta\right)
$$

because $x\left(\theta^{\prime}\right), t\left(\theta^{\prime}\right)$ satisfies $(2.3)$.

Now consider any incentive-compatible $x(\theta), t(\theta)$. This means that for all $\theta, \theta^{\prime}$,

$$
\mathrm{u}(\mathrm{x}(\theta), \mathrm{t}(\theta), \theta) \geq \mathrm{u}\left(\mathrm{x}\left(\boldsymbol{\theta}^{\prime}\right), \mathrm{t}\left(\theta^{\prime}\right), \theta\right)
$$

Delegate to the agent the right to choose within

$$
\{(x, t) \mid x=x(\theta), t=t(\theta), \text { for some } \theta\}
$$

Following $\mathrm{P}$-led renegotiation the agent will achieve the utility $\mathrm{u}(\mathrm{x}(\theta), \mathrm{t}(\theta), \theta)$ though perhaps via a different choice of actions $\bar{x}(\theta), \bar{t}(\theta)$ for the principal,

$$
f(\bar{t}(\theta), \bar{x}(\theta)) \geq f(x(\theta), t(\theta))
$$

Q.E.D.

Three remarks about this theorem should be made. First, the absence of $\theta$ from the utility function of the principal is crucial. Second, we cannot, a priori, rank the 
efficiency of "no contract" - this is the subject of section 4. Third, simple contracts with $\mathrm{P}$-led renegotiation are not flexible enough to reach the entire incentive compatible family. Therefore, if for some reason the principal cannot delegate discretion to the agent, he may in fact be better off giving the agent the power to lead the renegotiation phase, despite the general result of this theorem to the contrary - see section 6 . 


\section{The First Best}

Let us begin by examining the first-best solutions to the problem, and the applications given in section 2 .

The general problem, ex ante is

$$
\max \int U_{P} d F(\theta)
$$

subject to

$$
\int U_{A} d F(\theta) \geq \bar{w}
$$

The first-order conditions for this problem are

$$
\begin{gathered}
f_{x}\left(t^{*}(\theta), x^{*}(\theta)\right)+\lambda^{*} u_{x}\left(x^{*}(\theta), t^{*}(\theta), \theta\right)=0 \\
f_{t}\left(t^{*}(\theta), x^{*}(\theta)\right)+\lambda^{*} u_{t}\left(x^{*}(\theta), t^{*}(\theta), \theta\right)=0 \\
\int u\left(x^{*}(\theta), t^{*}(\theta), \theta\right)=\bar{w} .
\end{gathered}
$$

In the case of a buyer with unknown valuation facing a risk averse seller with constant unit costs, we have, in addition to (3.1),

$$
\begin{gathered}
f^{\prime}\left(t^{*}(\theta)-x^{*}(\theta)\right)=\lambda^{*} \\
\mathrm{f}^{\prime}\left(t^{*}(\theta)-x^{*}(\theta)\right)=\lambda^{*} u_{x}\left(x^{*}(\theta), \theta\right)
\end{gathered}
$$

Hence, eliminating $\lambda^{*}, \quad u_{x}\left(x^{*}(\theta), \theta\right)=1$.

In the case of a worker facing a firm with unknown productivity, we have 


$$
\begin{gathered}
-1+\lambda^{*} u_{x}\left(x^{*}(\theta), \theta\right)=0 \\
\mathrm{f}^{\prime}\left(\mathrm{t}^{*}(\theta)\right)-1=0
\end{gathered}
$$

Note that in each case the agent's utility at the first-best is monotone in $\theta$. This follows from the property that the cross-derivative $u_{x \theta}$ is positive for example, in the case of the buyer and seller;

$$
\begin{aligned}
& { }^{\mathrm{d}} \mathrm{U}_{\mathrm{A}} \frac{\left(\mathrm{x}^{*}(\theta), \mathrm{t}^{*}(\theta), \theta\right)}{\mathrm{d} \theta}=-\frac{\mathrm{dt}^{*}(\theta)}{\mathrm{d} \theta}+\mathrm{u}_{\mathrm{x}}\left(\mathrm{x}^{*}(\theta), \theta\right) \frac{\mathrm{dx} \mathrm{x}^{*}}{\mathrm{~d} \theta} \\
& +\mathrm{u}_{\theta}\left(\mathrm{x}^{*}(\theta), \theta\right)=u_{\theta}\left(\mathrm{x}^{*}(\theta), \theta\right)
\end{aligned}
$$

In the case of the worker and the firm,

$$
\begin{aligned}
& \frac{\mathrm{d}_{\mathrm{A}}\left(\mathrm{x}^{*}(\theta), \mathrm{t}^{*}(\theta), \theta\right)}{\mathrm{d} \theta}=\mathrm{u}_{\mathrm{x}}\left(\mathrm{x}^{*}(\theta), \theta\right) \frac{\mathrm{dx} \mathrm{x}^{*}(\theta)}{\mathrm{d} \theta}+\mathrm{u}_{\theta}\left(\mathrm{x}^{*}(\theta), \theta\right) \\
& \text { which is likewise positive because } \frac{\mathrm{d} \mathrm{x}^{*}}{\mathrm{~d} \theta} \frac{{ }_{\mathrm{u}}^{\mathrm{u} \theta}}{\mathrm{u} \times \mathrm{x}}>0 \text {. }
\end{aligned}
$$




\section{The Domination of "No Contract"}

In this section we show that having "no contract" is, under quite general conartions, dominated by a contract in which the agent is given the leadership power in the renegotiation phase. By virtue of theorem 1, therefore, we will have shown that "no contract" can never be the efficient form of contract. The optimal contract will, in general, be of the form of delegation and $\mathrm{P}$-led renegotiation.

The control of the relationship in the ex post bargaining phase, in practice, depends upon details of their specific irreversible investments and their foregone outside opportunities. There may be cases where the principal must give the agent the bargaining advantage in the renegotiation phase. The importance of the result in this section is that, in such cases, it is better for the principal to contract with such an agent than it is to refuse to contract at all.

One instance of this loss of bargaining power may arise when the principal is a worker contracting with a firm and the worker's unknown ability enters the firm's production function. Once the worker has worked for this firm for a while, long enough for his "ability", which may be the realization of his "long run potential", to become known, he may have lost his mobility or marketability in other jobs and may, therefore, be held to his contractual level of utility by the agent, his employer. According to the theorem of this section, it will al ways be more efficient, ex ante, for this worker to contract with the firm, rather than to wait until the uncertainty is resolved.

This result depends on some mild assumptions about the form of payoff functions. We first assume that both goods are "normal" for both players. That is, there are monotonic loci of pairs $(x, t)$ at which the marginal rates of substitution are constant. Thus,

$$
\frac{d}{d t}\left[\frac{-u}{u_{x}}-\right]>0
$$




$$
\begin{aligned}
& \frac{d}{d x}\left[\frac{-u_{t}}{u_{x}}\right]>0 \\
& \frac{d}{d t}\left[\frac{-f_{t}}{f_{x}}-\right]<0 \\
& \frac{d}{d x}\left[\frac{-f_{x}}{f_{x}}\right]<0
\end{aligned}
$$

These imply,

$$
\begin{aligned}
& u_{t} u_{t x}-u_{x} u_{t t}>0 \\
& u_{t} u_{x x}-u_{x} u_{t x}>0 \\
& f_{t} f_{t x}-f_{x} f_{t t}<0 \\
& f_{t} f_{x x}-f_{x} f_{t x}<0
\end{aligned}
$$

The principal result of this section can now be stated.

Theorem $\underline{2}$

Assuming (4.1) - (4.4), and appropriate boundary behavior for the derivatives of $\mathrm{f}$ and $u$ there exists a contract with A-led renegotiation which is superior for the principal to not offering any contract to the agent.

Proof

The proof proceeds constructively by defining a contract which involves A-led renegotiation and which dominates no contract. The contract will be denoted $\hat{x}, \hat{t}$. For each $\theta$, the agent will give the principal the utility $f(\hat{x}, \hat{t})$ by choosing an ex post 
efficient $\mathbf{x}(\theta), t(\theta)$. Thus, the significance of $\hat{x}, \hat{t}$ is that it guarantees a level of utility for the principal. The specific pair $\hat{x}, \hat{t}$ is not important. For each value of $\theta$ we will compare the utility level arrived at under the contract $\hat{x}, \hat{t}$ with the utility levels achieved under no contract. In the former case, the principal gets $f(\hat{x}, \hat{t})$ and the agent gets the utility that corresponds to this level, given $\theta$. In the latter case it is the agent's level that is invariant to $\theta$, being $\bar{w}$, and the principal's realized utility will increase with $\theta$.

We note that since the agent gets $\bar{w}$ on average in either contract, he will realize above $\overline{\mathrm{w}}$ when $\theta$ is high and below $\overline{\mathrm{w}}$ when $\theta$ is low. The idea of the proof is to show that under the contract, when $\theta$ is low, the principal gains at the agent's expense and that this gain is larger than the loss the principal sustains when at, high $\theta$, the agent's power in the renegotiation phase allows him to do better than $\bar{w}$. The method of proof is to examine the slope of the utility possibility set, for each $\theta$, in the region between the points realized by these two contracts. We will show that per unit change in the agent's utility, the principal's utility is more sensitive when $\theta$ is low than when $\theta$ is high. That is why the positive changes in the principal's utility outweigh the negative changes. We now proceed to this demonstration.

In the renegotiation phase, after the contract $\mathrm{x}, \mathrm{t}$ has been signed, the agent will solve

$$
\begin{gathered}
\max u(x, t, \theta) \\
\text { subject to } \\
f(x, t) \geq f(\hat{x}, \hat{t})
\end{gathered}
$$

Let the value of this problem be denoted $\phi(\hat{\mathrm{f}}(\hat{\mathrm{x}}, \hat{\mathrm{t}}), \theta)$.

Now consider the following system of equations:

$$
f_{x}(\hat{x}, \hat{t})+\hat{\lambda} u_{x}(\hat{x}, \hat{t}, \hat{\theta})=0
$$




$$
\begin{aligned}
& f_{t}(\hat{x}, \hat{t})+\hat{\lambda} u_{t}(\hat{x}, \hat{t}, \hat{\theta})=0 \\
& \mathrm{u}(\hat{\mathrm{x}}, \hat{\mathrm{t}}, \hat{\theta}) \quad=\overline{\mathrm{w}} \\
& \int \phi(\mathrm{f}(\hat{\mathrm{x}}, \dot{\mathrm{t}}), \theta) \mathrm{dF}(\theta)=\overline{\mathrm{w}}
\end{aligned}
$$

for the four unknowns $\hat{x}, \hat{t}, \hat{\theta}, \hat{\lambda}$. Under some technical, but ordinary, conditions on the boundary behavior of the partial derivatives of $f$ and $u$, a solution will exist.

The interpretation of these equations is as follows: Given $\dot{x}, \hat{t}$ we know that the solution of $(4.6-4.9)$ will generally result in $(x(\theta), t(\theta)) \neq(\hat{x}, \hat{t})$. However, there will be some value of $\theta$, called $\hat{\theta}$, at which $\hat{x} ; \hat{t}$ is ex post efficient and therefore at which it remains in force after renegotiation. In addition we know that the level of utility $f(\hat{x}, \hat{t})$ that the principal proposes to guarantee himself in the contract will provide the agent with the ex ante utility $\vec{w},(4.9)$. Equation (4.8) says that this level of ex ante utility is realized ex post at precisely the same $\hat{\theta}$ at which $\hat{x}, \hat{t}$ is invariant to renegotiation.

This contract $(\hat{x}, \hat{t})$ is generally not efficient in the ex ante sense that it is not the best A-led contract. However it always dominates "no contract" as we now show.

Let us write the first-order conditions for the problem (4.5)

$$
\begin{gathered}
\mu \mathrm{f}_{\mathrm{x}}(\mathrm{x}, \mathrm{t})+\mathrm{u}_{\mathrm{x}}(\mathrm{x}, \mathrm{t}, \theta)=0 \\
\mu \mathrm{f}_{\mathrm{t}}(\mathrm{x}, \mathrm{t})+\mathrm{u}_{\mathrm{t}}(\mathrm{x}, \mathrm{t}, \theta)=0 \\
\mathrm{f}(\mathrm{x}, \mathrm{t})=\mathrm{f}(\dot{\mathrm{x}}, \hat{\mathrm{t}})
\end{gathered}
$$

where $\mu$ is the Lagrange multiplier of the constraint. We know that 


$$
\phi_{\mathrm{f}}(\mathrm{f}(\dot{\mathrm{x}}, \hat{\mathrm{t}}), \theta)=-\mu(\theta)
$$

and that $\mu(\theta)>0$.

Let $\psi(u, \theta)$ be defined by

$$
\psi(\phi(\mathrm{f}, \theta), \theta)=\mathrm{f}, \text { for all } \mathrm{f}, \theta .
$$

Then

$$
\psi_{\mathrm{u}}(\mathrm{u}, \theta)=\frac{1}{\phi_{\mathrm{f}}(\psi(\mathrm{u}, \theta), \theta)}
$$




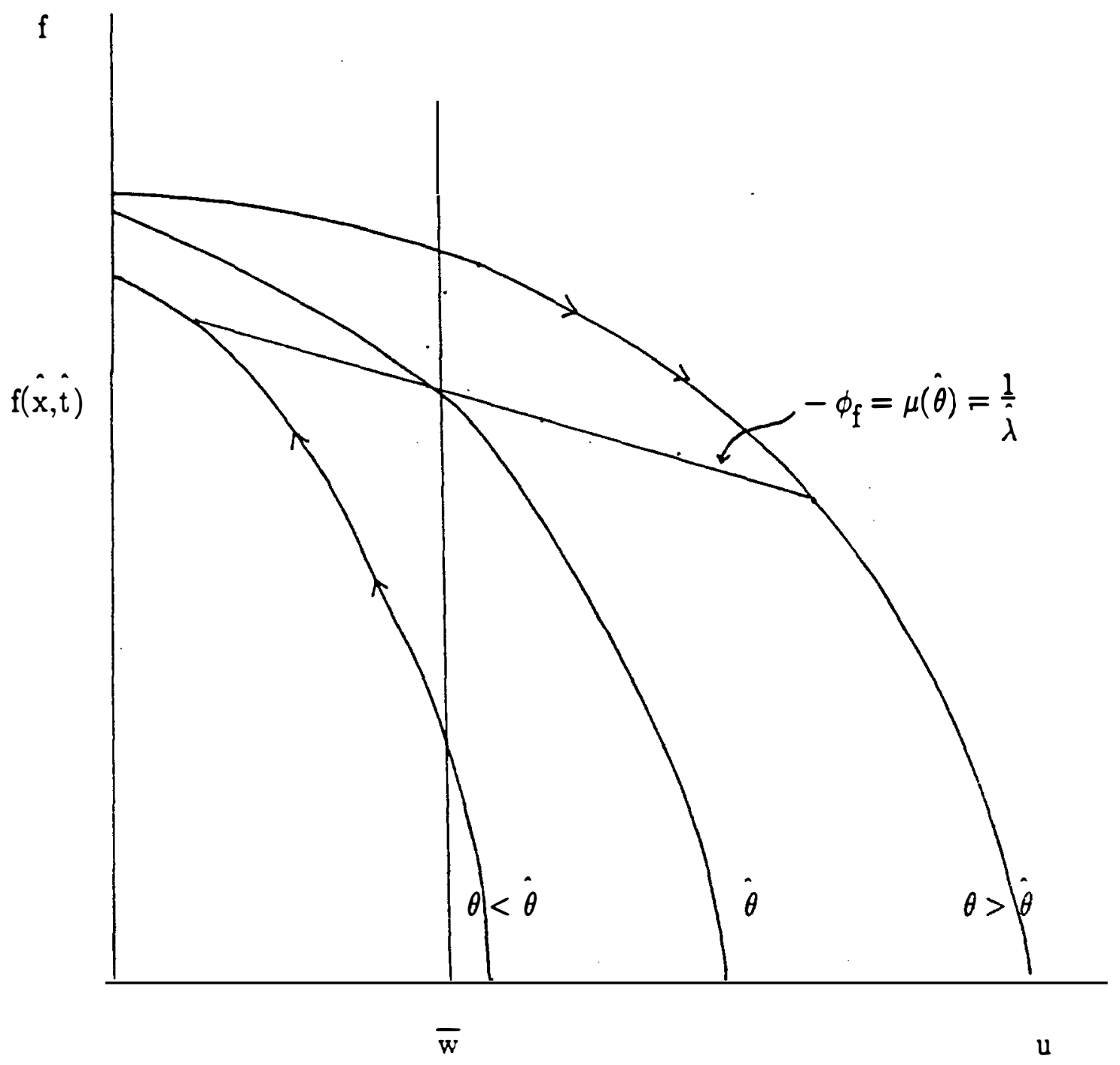

FIGURE 4 
Let us compare the principal's utility under this contract to that obiained under no contract. The change in the principal's utility is

$$
\iint_{\frac{w}{u}}^{\phi(f(\hat{x}, \hat{t}), \hat{\theta})} \psi_{u}(u, \theta) d u d F(\theta)
$$

We can divide the integral over $\theta$ into two parts, above and below $\hat{\theta}$ :

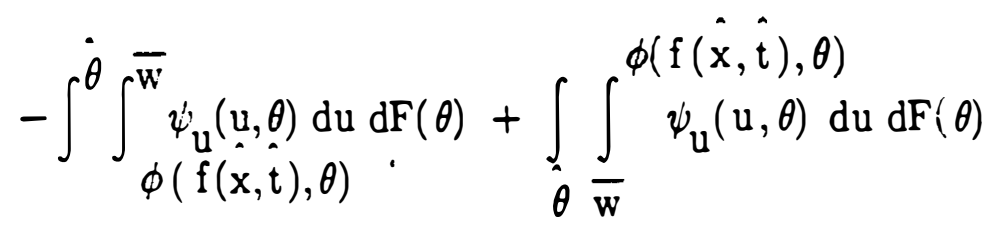

We show that in the range of the first double integral, where

$$
\begin{gathered}
\mathrm{u}(\mathrm{x}(\theta), \mathrm{t}(\theta), \theta)<\overline{\mathrm{w}} \\
\theta<\dot{\theta}
\end{gathered}
$$

that

$$
\psi_{\mathrm{u}}(\mathrm{u}(\mathrm{x}(\theta), \mathrm{t}(\theta), \theta), \theta)<-\hat{\lambda}
$$

and, conversely, in the range of the second double integral where

$$
\begin{gathered}
\mathrm{u}(\mathrm{x}(\theta), \mathrm{t}(\theta), \theta)>\overline{\mathrm{w}} \\
\theta>\hat{\theta}
\end{gathered}
$$

that

$$
\psi_{\mathrm{u}}(\mathrm{u}(\mathrm{x}(\theta), \mathrm{t}(\theta), \theta), \theta)>-\dot{\lambda}
$$


Note that

$$
\mu(\dot{\theta})=\frac{1}{\dot{\lambda}}
$$

and that

$$
\psi_{u}(u, \theta)=\frac{1}{\phi_{f}(\psi(u, \theta), \theta)}=-\frac{1}{\mu(\theta)}
$$

Therefore (4.15) and (4.16) will be proven if we can demonstrate that

$$
\frac{\mathrm{d} \mu(\theta)}{\mathrm{d} \theta}<0 .
$$

Differentiate the system $(4.10-4.12)$ totally and apply Cramer's rule, obtaining

$$
\begin{aligned}
\Delta \frac{d \mu}{d \theta} & =-u_{x \theta}\left(f_{x}\left(\mu f_{x t}+u_{x t}\right)-f_{x}\left(\mu f_{t t}+u_{t t}\right)\right. \\
& +u_{t \theta}\left(f_{t}\left(\mu f_{x x}+u_{x x}\right)-f_{x}\left(\mu f_{x t}+u_{x t}\right)\right)
\end{aligned}
$$

where

$$
\Delta=\operatorname{det}\left[\begin{array}{lll}
\mu f_{x x}+u_{x x} & \mu f_{x t}+u_{x t} & f_{x} \\
\mu f_{x t}+u_{x t} & \mu f_{t t}+u_{t t} & f_{t} \\
f_{x} & f_{t} & 0
\end{array}\right]<0
$$

At the ex post efficient point, $\dot{\theta}$, we can use $(4.10)$ and $(4.11)$ to rewrite $(4.17)$ as

$$
\begin{gathered}
\Delta \frac{d \mu}{d \theta}=-u_{x \theta}\left(\mu\left(f_{t} f_{x t}-f_{x} f_{t t}\right)-\frac{1}{\mu}\left(u_{t} u_{x t}-u_{x} u_{t t}\right)\right) \\
+u_{t \theta}\left(\mu\left(f_{t} f_{t x}-f_{x} f_{x t}\right)-\frac{1}{\mu}\left(u_{t} u_{x x}-u_{x} u_{x t}\right)\right)
\end{gathered}
$$


and, under our normality condition, $(4.1-4.4)$, the right hand side of this equation is positive, hence $\frac{d \mu}{d \theta}<0$, and hence (4.15) and (4.16) hold under the specified conditions.

Now we can bound (4.14) using (4.15),

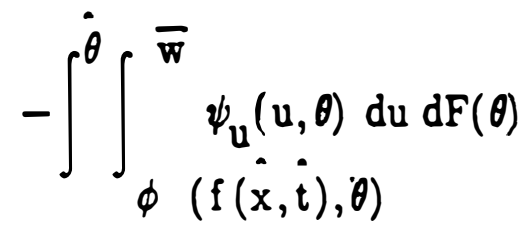$$
\geq \int^{\dot{\theta}} \int_{\vec{w}}^{\phi(f(x, \dot{t}), \theta)} \lambda d u d F(\theta)
$$

$$
=-\lambda \int^{\dot{\theta}}[\phi(\mathrm{f}(\dot{x}, \dot{\mathrm{t}}), \theta)-\bar{w}] \mathrm{dF}(\theta)
$$

In the range of the second double integral (4.16) implies

$$
\begin{gathered}
\int_{\dot{\theta}} \int_{\mathrm{w}}^{\phi(\mathrm{f}(\dot{\mathrm{x}}, \dot{\mathrm{t}}), \theta)} \psi_{\mathrm{u}}(\mathrm{u}, \theta) \mathrm{dud} \mathrm{d}(\theta) \\
\geq \int_{\dot{\theta}} \int_{\mathrm{w}}^{\phi(\mathrm{f}(\dot{\mathrm{x}}, \dot{\mathrm{t}}), \theta}(-\lambda) \mathrm{dudF}(\theta) \\
=-\lambda \int_{\dot{\theta}}[\phi(\mathrm{f}(\dot{\mathrm{x}}, \dot{\mathrm{t}}), \theta)-\overline{\mathrm{w}}] \mathrm{dF}(\theta)
\end{gathered}
$$

Combining the lower bounds (4.18) and (4.19) we have that (4.13) is bounded below by 


$$
\begin{aligned}
& \left.-\lambda \int \phi(f(\dot{x}, \dot{\mathrm{t}}), \theta)-\overline{\mathrm{w}}\right) d F(\theta) \\
& =0 \text {. } \\
& \text { Q.E.D. }
\end{aligned}
$$

by virtue of (4.9). 


\section{Implementation of First-Best Allocations}

First, we can observe that only the mechanisms of delegation and $\mathrm{P}$-led renegotiation have the potential of reaching the first best in generic situations. The no contract mechanism produces a constant (in $\theta$ ) utility level for the agent, the A-led renegotiation produces a constant utility level for the principal, two unlikely events in the first best. The incentive compatible allocations corresponding to delegation without renegotiation require a very particular relationship between $x(\theta)$ and $t(\theta)$ namely

$$
x^{\prime}(\theta) u_{x}(x(\theta), t(\theta), \theta)+t^{\prime}(\theta) u_{t}(x(\theta), t(\theta), \theta)=0 \text { almost everywhere }
$$

which will not be satisfied in general.

Therefore let us consider delegation with $\mathrm{P}$-ied renegotiation and consider $\mathrm{w}^{*}(\theta)$ a level of utility achieved by the agent in a first best allocation.

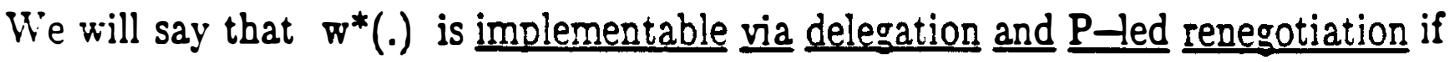
there exists an incentive compatible mechanism $(x(\theta), t(\theta)): \theta \rightarrow \mathbb{R}^{2}$ such that:

$$
\mathrm{u}(\mathrm{x}(\theta), \mathrm{t}(\theta), \theta)=\mathrm{w}^{*}(\theta) \quad \theta \in \theta .
$$

The principal then proposes this mechanism which provides the status quo levels $w^{*}(\theta)$ for the agent and ex post maximizes his objective function under the agent's individual rationality constraint:

$$
\mathrm{u}(\mathrm{x}, \mathrm{t}, \theta) \geq \mathrm{w}^{*}(\theta)
$$

reaching in this way an efficient allocation in which the agent obtains $\mathrm{w}^{*}(\theta)$. 


$$
x^{\prime}(\theta) u_{x}(x(\theta), t(\theta), \theta)+t^{\prime}(\theta) u_{t}(x(\theta), t(\theta), \theta)=0 \text { almost everywhere }
$$

Under the single crossing property (SCP), $\frac{\partial \cdot}{\partial \theta}\left[-\frac{u_{x}}{u_{t}}\right]>0, \quad \forall x, t, \theta$, we know (Guesnerie and Laffont (1984)) that the second order condition:

$$
x^{\prime}(\theta) \geq 0
$$

together with (5.2) yield necessary and sufficient conditions for incentive compatibility.

Therefore, we have the desired result if the solution $x(\theta)$ obtained from $(5.1)(5.2)$ satisfies (5.3).

Differentiating (5.1) and using (5.2) gives:

$$
u_{\theta}(x(\theta), t(\theta), \theta)=w^{* 1}(\theta)
$$

Differentiating again (5.4) we have:

$$
u_{\theta \theta}(x(\theta), t(\theta), \theta)-x^{\prime}(\theta) \cdot u_{t}(x(\theta), t(\theta), \theta) \cdot \frac{\partial}{\partial \theta}\left[-\frac{u_{x}}{u_{t}} \frac{(x(\theta), t(\theta), \theta)}{(x(\theta), t(\theta), \theta)}\right]=w^{* \prime \prime}(\theta)
$$

or in view of (SCP) and $u_{t}<0$,

$$
\operatorname{sign} x^{\prime}(\theta)=\operatorname{sign}\left[w^{* \prime \prime}(\theta)-u_{\theta \theta}(x(\theta), t(\theta), \theta)\right]
$$

F'rom (5.5) we have imrnediately: 
Theorem 3 . Under the single crossing property and $u_{\theta \theta}=0$, the first best agent's utility profile $w^{*}(\cdot)$ is implementable via delegation and $\mathrm{P}$-led renegotiation iff $\mathrm{w}^{* \boldsymbol{l}}(\theta) \geq 0$ and $\mathrm{w}^{* *}(\theta) \geq 0$ for any $\theta$.

We will restrict now the analysis to the utility functions

$$
-\mathrm{t}+\theta \mathrm{v}(\mathrm{x}) \quad \mathrm{v}^{\prime}>0 \mathrm{v}^{\prime}<0
$$

which satisfy the assumptions of Theorem 3 .

In more general cases the argument above does not enable us to develop a necessary and sufficient condition because $\mathrm{u}_{\theta \theta}$ is a function of the unknown mechanism $(x(\cdot), t(\cdot))$.

Let us call $\phi(\mathrm{w}, \theta)$ the solution of

$\operatorname{Max} f(t, x)$

$$
\mathrm{u}(\mathrm{x}, \mathrm{t}, \theta)=\mathrm{w}
$$

i.e. the principal's utility level after renegotiation if the status quo level is $w$ for the agent.

Under the assumptions of Theorem 3 , and assuming $\Theta \equiv[\underline{\theta}, \bar{\theta}]$, the optimization program of the principal can be written.

$$
\underset{\mathrm{w}(\cdot)}{\operatorname{Max}} \int_{\underline{\theta}}^{\bar{\theta}} \phi(\mathrm{w}(\theta), \theta) \mathrm{dF}(\theta)
$$

subject to

$$
\begin{gathered}
\int_{\underline{\theta}}^{\bar{\theta}} \mathrm{w}(\theta) \mathrm{dF}(\theta)=\overline{\mathrm{w}} \\
\mathrm{w}^{\prime}(\theta) \geq 0 \text { and } \mathrm{w}^{\prime}(\theta) \geq 0
\end{gathered}
$$


Defining two state variables $\mathbf{w}(\theta)$ and $z(\theta)=w^{\prime}(\theta)$ and the control $\mu(\theta)$ we can rewrite this program:

$$
\begin{aligned}
& \underset{\mu(\cdot)}{\operatorname{Max}_{\underline{\theta}}} \int_{\underline{\theta}}^{\bar{\theta}} \phi(\mathrm{w}(\theta), \theta) d F(\theta) \\
& \int_{\dot{\mathrm{w}}}^{\bar{\theta}} \mathrm{w}(\theta) \mathrm{d}(\theta)=\underline{\underline{ }}(\theta) \quad\left(\mathrm{v}_{1}(\theta)\right) \\
& \dot{\mathrm{z}}(\theta)=\mu(\theta) \quad\left(\mathrm{v}_{2}(\theta)\right)
\end{aligned}
$$

$$
\begin{aligned}
& \mu(\theta) \geq 0 \\
& z(\theta) \geq 0
\end{aligned}
$$

The shape of the optimal solution will depend on which of the constraints (5.7) or (5.8) is binding. If none of the constraints is binding, the first best is achieved and we have:

$$
\begin{gathered}
\phi_{w}\left(w^{*}(\theta), \theta\right)=\lambda^{*} \quad \text { for any } \theta \\
\int_{\underline{\theta}}^{\bar{\theta}} w^{*}(\theta) d F(\theta)=\bar{w}
\end{gathered}
$$

Suppose now that the first best is increasing so that constraint (5. $i$ ) is not binding. 
The Hamiltonian is then:

$$
\mathrm{H}=\phi(\mathrm{w}(\theta), \theta) \mathrm{f}(\theta)-\lambda \mathrm{w}(\dot{\theta}) \mathrm{f}(\theta)+\mathrm{v}_{1}(\theta) z(\theta)+\mathrm{v}_{2}(\theta) \mu(\theta)
$$

From the Pontryagin principle we get:

with the transversality conditions:

$$
\begin{aligned}
& \dot{v}_{1}=\left(\lambda-\phi_{w}^{\prime}\right) f \\
& \dot{v}_{2}=-v_{1}
\end{aligned}
$$

$\mathrm{v}_{1}(\underline{\theta})=\mathrm{v}_{1}(\bar{\theta})=\mathrm{v}_{2}(\underline{\theta})=\mathrm{v}_{2}(\bar{\theta})=0$

Maximization of (5.9) with respect to $\mu$ gives:

$$
\mathrm{v}_{2} \leq 0 \text { and } \mu=0 \text { if } \mathrm{v}_{2}<0
$$

Whenever the optimal solution $\overline{\mathrm{w}}(\cdot)$ is strictly convex on an interval it entails the same constant value $\phi_{w^{*}}$. From $(5.13), \bar{w}^{*}>0$ implies $\mu>0$ which implies $v_{2}=0$ on this interval. (5.11) implies $v_{1}=0$ hence $\phi_{w}^{\prime}=\lambda$ on this interval.

From (5.13) we see that when the solution is not strictly convex it is linear. Let $\theta_{0} \theta_{1}$, such an interval where it is not convex. Integrating (5.10) between $\theta_{0}$ and $\theta_{1}$ and using the continuity of the Pontryagin multipliers at $\theta_{0}$ and $\theta_{1}$ we have: 


$$
v_{1}\left(\theta_{1}\right)-v_{1}\left(\theta_{0}\right)=0=\int_{\theta_{0}}^{\theta_{1}}\left(\lambda-\phi_{W}^{\prime}\right) d F .
$$

As the state variables are con tinuous we have

$$
\bar{w}^{\prime}\left(\theta_{0}\right)=\overline{\mathrm{w}}^{\prime}\left(\theta_{1}\right)
$$

to complete the characterization of the interval $\left(\theta_{0}, \theta_{1}\right)$ (see Fig. 5) 


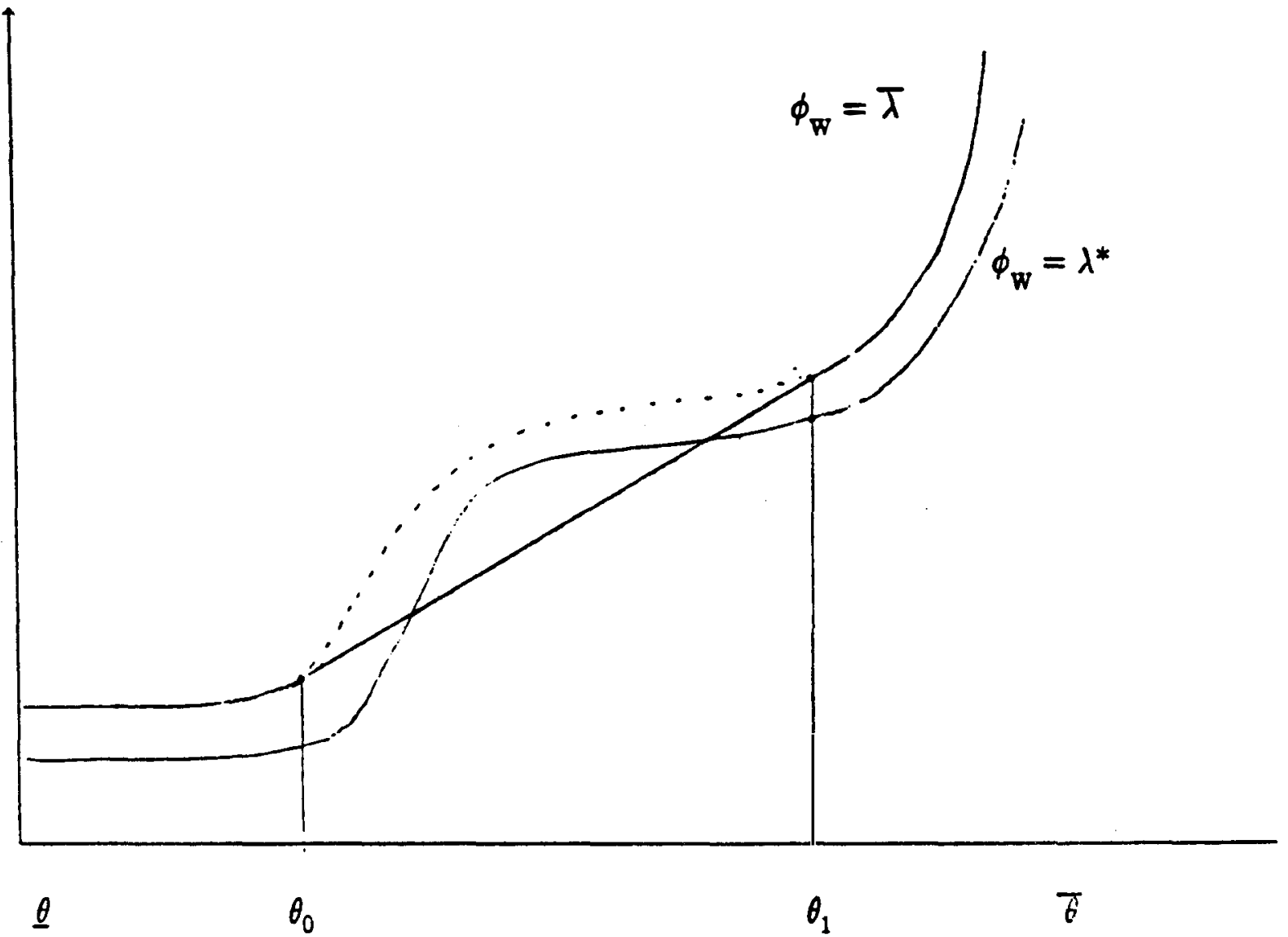

FIGURE $\underline{5}$ 
Observe that the linear piece in fig.5 can only be obtained from a simple contract $\dot{x}, \dot{t}$ since $\dot{x}, \dot{t}$ generates a linear utility level,

$$
w(\theta)=\theta v(\dot{x})-\dot{t}
$$

and if $\mathbf{x}$ were not constant $\mathrm{w}(\theta)$ would not be linear.

Suppose now that the first best is convex but first decreasing and then increasing. Similar arguments as above show then that when it is increasing, the optimal solution is analogous to the first best with a different value of the multiplier and is flat elsewhere (See fig.6). The interval $\left(\underline{\theta}, \theta_{0}\right)$ is determined by the condition:

$$
\int_{\underline{\theta}}^{\theta_{0}}\left(\lambda-\phi_{w}^{\prime}\right) d F(\theta)=0
$$

When $v(0)=0$, the constant piece has the interpretation of a cancellation of delivery $(x=0)$ that the agent selects with an associated transfer $t$ determining the level of the payment. If $\mathrm{t}<0$ it can be interpreted as a cancellation fee that the agent must pay when he chooses not to transact. If $t>0$, it can be interpreted as an hostage given by the principal to encourage the agent to sign ex ante (see Williamson (1983)). When both constraints (5.7)(5.8) may be binding the solution is more difficult to describe because the contraints on state variables may induce jumps at the optimal solution. 


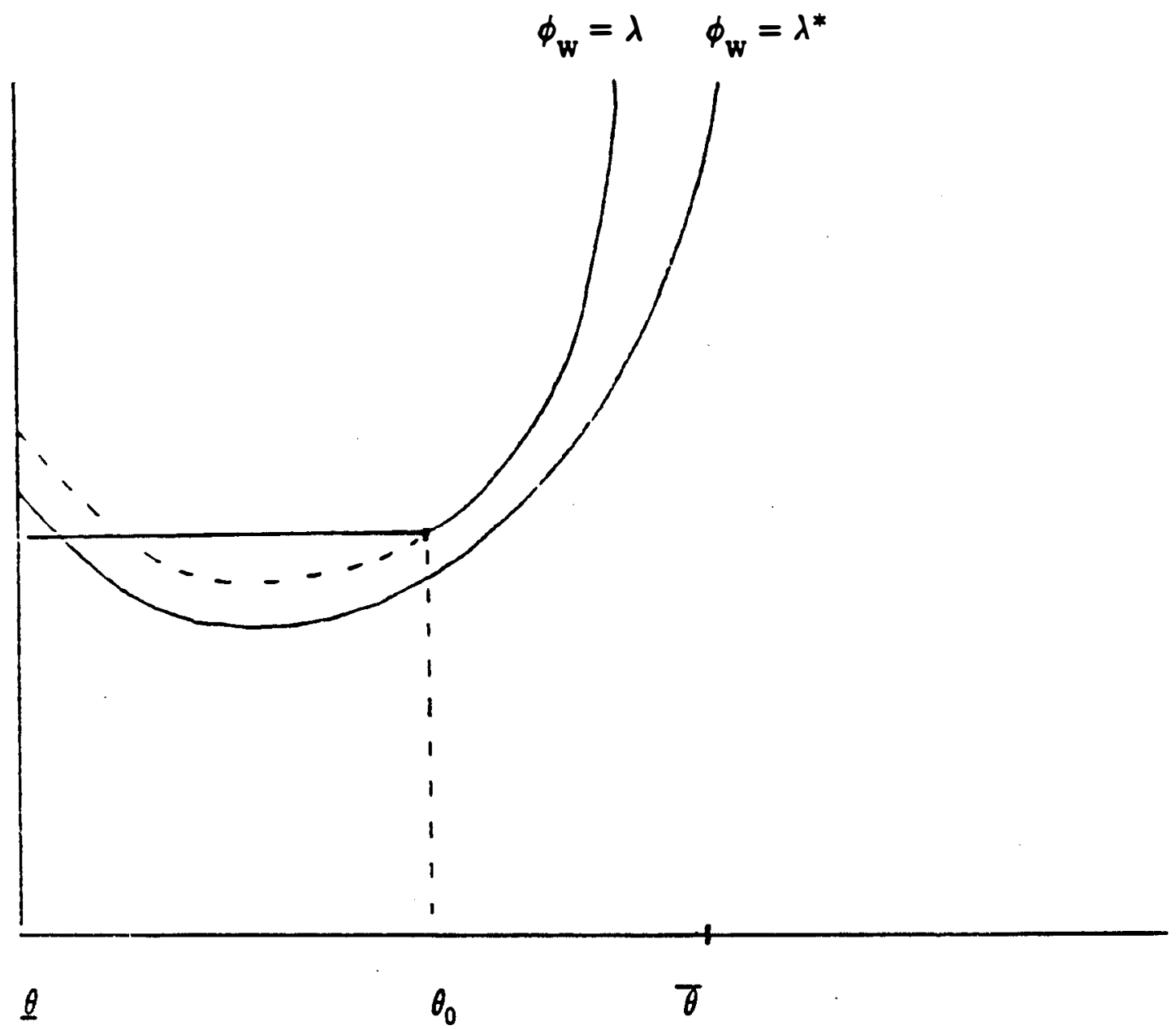

FIGURE $\underline{6}$ 
The question of implementability of first best allocations reduces then to the characterization of cases when the first best utility profile of the agent.is increasing and convex.

An interesting result is obtained when the principal's utility function is:

$$
f(t)-x
$$

We then have:

Theorem 4. For the utility functions $(5.6)(5.14)$ the first best allocation is implementable via delegation and $\mathrm{P}$-led renegotiation iff the index of absolute risk aversion of $\mathrm{v}$ is decreasing:

Proof. In this case the first best is such that

$$
\theta v^{\prime}\left(x^{*}(\theta)\right)=\lambda^{*} \text { for any } \theta
$$

Hence,

$$
x^{* \prime}=-\frac{v^{\prime}}{\theta v^{\prime}} ; x^{* *}=\frac{2 v^{\prime}}{\theta^{2} v^{\cdot}}-\frac{v^{\prime^{2}} v^{\prime} \prime^{\prime}}{\theta^{2} v^{*}}
$$

In the first best $\mathrm{f}^{\prime}\left(\mathrm{t}^{*}(\theta)\right)=\lambda^{*}$; therefore $\mathrm{t}^{*}$ is constant. Differentiating twice the agent's utility function we obtain:

$$
\frac{d^{2} w^{*}(\theta)}{d \theta^{2}}=v^{\prime}\left(x^{*}(\theta)\right) x^{* \prime}(\theta)+\theta v^{*}\left(x^{*}(\theta)\right)\left(x^{* \prime}(\theta)\right)^{2}
$$

$$
+\theta v^{\prime}\left(x^{*}(\theta)\right) x^{* \cdot}(\theta)+v^{\prime}\left(x^{*}(\theta)\right) x^{* \prime}(\theta)
$$


The differentiation of (5.15) shows that the first two terms of (5.17) cancel. Using (5.16) we obtain

$$
\frac{d^{2} w^{*}(\theta)}{d \theta^{2}}=-\lambda^{*} \frac{v^{\prime}}{\theta v^{*}} \frac{d}{d x}\left[-\frac{v^{\prime}}{v^{\prime}}\right]>0 .
$$

Hence the result from Theorem 3

$$
\text { Q.E.D. }
$$




\section{Examples}

From section 2 we know that A-led renegotiation, being a special case of incentive compatible mechanism, is dominated by a contract of the type delegation and P-led renegotiation. However, authentic delegation may be necessary, i.e. A-led renegotiation may not be dominated by any simple contract with renegotiation. We provide below such an example.

Examole 1: $\quad \mathrm{u}(\mathrm{x}, \mathrm{t}, \theta)=-\mathrm{t}+\theta_{\mathrm{v}}(\mathrm{x})$

$$
f(t, x)=f(t-x)
$$

In the first best we have $f^{\prime}\left(t^{*}(\theta)-x^{*}(\theta)\right)=$ constant and therefore $f\left(t^{*}(\theta)-x^{*}(\theta)\right)=$ constant.

With a constant contract $(\hat{x}, \hat{t})$ followed by renegotiation, the principal solves:

$$
\begin{gathered}
\operatorname{Max} f(t-x) \\
\theta v(x)-t \leq \theta v(\dot{x})-\dot{t}
\end{gathered}
$$

reaching a level of utility which varies with $\theta$ and is therefore different from the first best level.

To implement the first best allocation with a simple contract with A-led renegotiation, the principal can choose $\dot{x}, \dot{t}$ such that

$$
f(\dot{t}-\dot{x})=f\left(t^{*}(\theta)-x^{*}(\theta)\right)=\text { const. }
$$


Then the agent solves:

$$
\begin{gathered}
\operatorname{Max}-t+\theta v(x) \\
\text { subject to } f(t-x) \geq f\left(t^{*}(\theta)-x^{*}(\theta)\right)
\end{gathered}
$$

and reaches the first best allocation.

It should be clear that the mechanism delegation and $\mathrm{P}$-led renegotiation is more powerful than a contract with agent's control. We illustrate this point with the example used in theorem 4.

Example 2:

$$
\begin{gathered}
\mathrm{u}(\mathrm{x}, \mathrm{t}, \theta)=-\mathrm{t}+\theta \mathrm{v}(\mathrm{x}) \\
\mathrm{f}(\mathrm{t}, \mathrm{x})=\mathrm{f}(\mathrm{t})-\mathrm{x}
\end{gathered}
$$

Under the increasing absolute risk aversion of $\mathbf{v}$ the first best is reached by delegation and $\mathrm{P}$-led renegotiation. As $\mathrm{t}^{*}$ is constant in the first best and $\mathrm{x}^{*}$ increasing the principal's utility level is decreasing in $\theta$ in the first best and we know that A-led renegotiation implements only constant utility levels for the principal. Indeed this latter mechanism is just a particular incentive compatible mechanism and here the first best is not incentive compatible and requires renegotiation. This is because whenever $t^{*}$ is constant $x^{*}$ must be constant to insure incentive compatibility.

On the contrary, in example 1 renegotiation is not really needed because the first best is incentive compatible. From efficiency,

$$
f=\lambda \text { and } f=\lambda Q^{\prime}(x)
$$


Incentive compatibility requires:

$$
-t^{\prime}+\theta v^{\prime}(x) x^{\prime}=0
$$

or from efficiency

$$
x^{\prime}-t^{\prime}=0
$$

But as in the first best the principal's utility is constant $x^{\prime}=t^{\prime}$.

Implementation of a given first best allocation must be distinguished from implementation of first best levels of utilities when first best allocations are not unique. The following example illustrates that implementation of a given first best allocation is much more demanding that implementation of first best levels of utility.

Examole 3

$$
\begin{gathered}
\mathrm{u}(\mathrm{x}, \mathrm{t}, \theta)=-\mathrm{t}+\theta \mathrm{v}(\mathrm{x}) \\
\mathrm{f}(\mathrm{t}, \mathrm{x})=\mathrm{t}+\mathrm{f}(\mathrm{x})
\end{gathered}
$$

In a first best allocation $\mathrm{f}^{\prime}\left(\mathrm{x}^{*}(\theta)\right)=\theta \mathrm{v}^{\prime}\left(\mathrm{x}^{*}(\theta)\right)$ but $\mathrm{t}^{*}(\theta)$ is only constrained by

$$
\int \mathrm{t}^{*}(\theta) \mathrm{dF}(\theta)=-\overline{\mathrm{w}}+\int \theta \mathrm{v}\left(\mathrm{x}^{*}(\theta)\right) \mathrm{dF}(\theta)=\mathrm{K}
$$

One particular first best allocation is then

$$
\mathrm{t}^{*}(\theta)=\mathrm{K} \forall \theta, \mathrm{x}^{*}(\theta) \text { such that } \mathrm{f}^{\prime}(\mathrm{x})=\theta^{\prime}(\mathrm{x})
$$

This allocation is implementable via delegation and $\mathrm{P}$-led renegotiation iff 


$$
\frac{d^{2}}{d \theta^{2}}\left(-K+\theta v^{\prime}\left(x^{*}(\theta)\right)\right) \geq 0
$$

or after a few manipulations

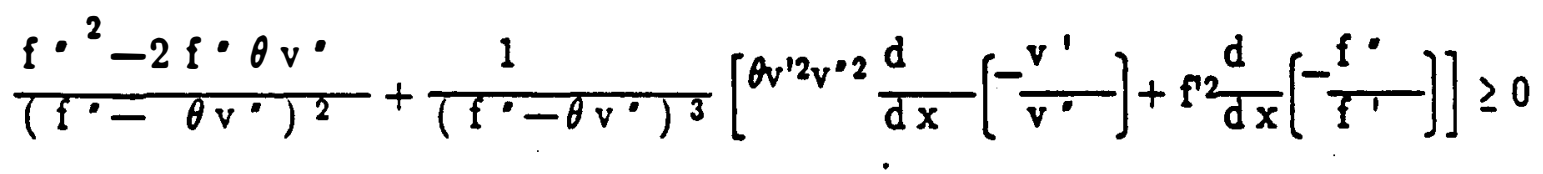

which obtains under our assumptions if $\frac{d}{d x} \cdot\left(-\frac{v^{\prime}}{v^{\prime}}\right]>0$ (as in Theorem 4) and moreover if $\frac{d}{d x}\left[-\frac{f^{\circ}}{f^{\prime}}\right]>0$.

However, first best level of utilities are always implemented with A-led renegotiation. The principal chooses $\dot{x}, \dot{t}$ such that

$$
\dot{t}-f(\dot{x})=\int\left[t^{*}(\theta)-f\left(x^{*}(\theta)\right)\right] d F(\theta)=K
$$

Then the agent selects the efficient $x^{*}(\theta)$ and chooses

$$
t^{*}(\theta)=f\left(x^{*}(\theta)\right)-\int f\left(x^{*}(\theta)\right) d F(\theta)+K
$$

which gives to him and to the principal the same expected utility level as in any first best allocation. 


\section{REFERENCES}

Aghion, P. and P. Bolton (1986), "An 'Incomplete Contracts' Approach to Bankruptcy and the Optimal Financial Structureof the Firm", mimeo.

Bull, C. (1983), "Implicit Contract in the Absence of Enforcement and Risk Aversion", American Economic Review, 83, 658-671.

Bull, C. (1987), "The Existence of Self-Enforcing Implicit Contracts", Quarterlv Journal of Economics, 83, 658-671.

Grossman, S. and O. Hart (1986), "The. Costs and Benefits of Ownership: A Theory of Vertical and Lateral Integration", Journal of Political Economy, 94, 691-719.

Grossman, S. and O. Hart (1987), "One Share/One Vote and the Market for Corporate Control", mimeo, M.I.T.

Grout, P. (1984), "Investment and Wages in the Absence of Binding Contracts: A Nash Bargaining Approach", Econometrica, 52, 449-460.

Guesnerie, R. and J.J. Laffont (1984) "A Complete Solution to a Class of Principal Agent

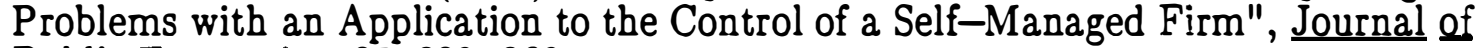
Public Economics, 25, 329-369.

Hart, O. and J. Moore (1985), "Incomplete Contracts and Renegotiation", mimeo, London School of Economics.

Huberman, G. and C. Kahn (1986a), "Limited Contract Enforcement and Strategic Renegotiation", mimeo.

Huberman, G. and C. Kahn (1986a), "Strategic Renegotiation and Contractual Simplicity", mimeo.

Maskin, E. (1985), "The Theory of Implementation in Nash Equilibrium: A Survey", in L. Hurwicz, D. Schmeidler and H. Sonnenschein (eds.), Social Goals and Social Organization Volume in Memory of E. Pazner, Cambridge University Press.

Moore, J. and R. Repullo (1985), "Subgame Perfect Implementation", London School of Economics and Political Science, mimeo.

Tirole, J. (1984) "Procurement and Renegotiation", Journal of Political Economv, $94,235-259$.

Williamson, O. (1983), "Credible Commitments: Using Hostages to Support Exchange", American Economic Review, 73, 519-540. 